\title{
LEGUMINOSAS DA FLORA FLUMINENSIS - J.M. DA C. VELLOZO - LISTA ATUALIZADA DAS ESPÉCIES ARBÓREAS ${ }^{1}$
}

Recebido em 22.08.94. Aceito em 08.05.95.

Haroldo C. de Lima²

\begin{abstract}
RESUMO - (Leguminosas da Flora Fluminensis - J.M.C. Vellozo - Lista atualizada das espécies arbóreas). As espécies arbóreas de Leguminosae descritas na Flora Fluminensis são revisadas nos seus aspectos nomenclaturais. Duas novas combinações (Tachigali paratyensis e Lonchocarpus cultratus) e alguns novos sinônimos são propostos e observações sobre as datas de publicação, os tipos e os locais de coletas das plantas são apresentadas.
\end{abstract}

Palavras-chave: Leguminosae, Fabaceae, Taxonomia, Flora, Rio de Janeiro, Brasil.

\begin{abstract}
Legums of the Flora Fluminensis - J.M.C. Vellozo - Updated list of tree species). The tree species of Leguminosae described in Flora Fluminensis are reviewed in regard to nomenclatural aspect. Two new combinations (Tachigali paratyensis e Lonchocarpus cultratus) and some synonimous are proposed and observations on publication dates, types and localities of plant collections are presented.
\end{abstract}

Key-words: Leguminosae, Fabaceae, Taxonomy, Flora, Rio de Janeiro, Brazil.

\section{Introdução}

A Flora Fluminensis, a monumental obra de Frei José Mariano da Conceição Vellozo, é o marco inicial da nomenclatura das plantas ocorrentes no estado do Rio de Janeiro. Embora o problema da data efetiva da publicação de seu texto e de suas estampas já tenha sido amplamente debatido (Carauta 1969, 1972), ainda permanecem algumas dúvidas sobre as prioridades dos gêneros e espécies divulgadas neste valioso trabalho. Para isto, muito tem contribuido a dificuldade na delimitação dos táxons devido ao extravio dos tipos e aos parcos conhecimentos sobre os locais onde Frei Vellozo fez suas coleções botânicas.

O estudo das Leguminosas arbóreas do Brasil Sudeste, projeto de pesquisa que esta sendo desenvolvido no Jardim Botânico do Rio de Janeiro, tornou possível um

\footnotetext{
' Trabalho apresentado no XLIII Congresso Nacional de Botânica, Aracajú, SE.

${ }^{2}$ Jardim Botânico do Rio de Janeiro/IBAMA, Rua Pacheco Leão n. 915, 22460-030, Rio de Janeiro, Brasil
} 
levantamento detalhado dos táxons ocorrentes no Estado do Rio de Janeiro. Os dados obtidos neste levantamento foram confrontados com os textos e as estampas da Flora Fluminensis para uma revisão e atualização nomenclatural dos binômios.

Os resultados são aqui apresentados na forma de uma lista atualizada, onde as espécies são citadas pelas referências de Vellozo $(1829,1831,1881)$ e acompanhadas da nomenclatura atual e de algumas observações taxonômicas. Como complemento, a fim de esclarecer certas questões ligadas às coleções botânicas, comentários são feitos sobre as datas efetivas de publicação, locais de coleta e tipos da Flora Fluminensis.

\section{Alguns comentários sobre a Flora Fluminensis}

As datas efetivas de publicação

Os trabalhos iniciais de Frei Vellozo remontam ao ano de 1782, quando o ViceRei D. Luiz de Vasconcelos e Souza deu ordens para que fossem realizadas excursões em toda a província do Rio de Janeiro e se reunissem os resultados numa obra a ser intitulada Flora Fluminensis (Stellfeld 1942). A conclusão dos trabalhos coincidiu com o término do mandato do Vice-Rei, quando os originais foram entregues juntamente com a carta de Frei Vellozo datada de 27 de junho de 1790.

Um longo caminho foi percorrido pelos originais (Borgmeier 1961, Carauta, $1969 ; 1972)$ até a publicação em partes, conforme é sumarizado abaixo:

Texto incompleto ( $1^{\circ}$ edição) - 07.setembro a 28 .novembro. 1829

Texto completo ( $2^{\circ}$ edição) - 08.julho. 1881

Estampas - 29.outubro.1831

Os locais de coleta

A "expedição botânica" instituida para a coleta, ilustração e descrição das plantas para a Flora Fluminensis percorreu durante cerca de 6 anos diversos recantos da então província do Rio de Janeiro (Damasceno 1977). Stellfeld (1942) nos dá conta que foram percorridas matas e praias em todas as direções e visitados locais como Paratí, Rio Paraiba do Sul e Paranapiacaba. Alguns trechos da expedição foram confirmados por documento recentemente encontrado na Biblioteca Nacional (Damaceno, 1.c.), revelando que em setembro de 1788 a expedição com mais de 40 pessoas encontrava-se entre Ilha Grande e Santos. Portanto, é provável que nesta época os limites entre as provícias não eram muito precisos e algumas espécies descritas na Flora Fluminensis tenham sido coletadas em áreas adjacentes ao estado do Rio de Janeiro, porém atualmente situadas no estado de São Paulo. A referência geográfica "pagum Cunha", atual cidade de Cunha - SP (Figura 1), citada como localidade de Trifolium mediterraneum, está de acordo com esta última observação.

Os hábitats assinalados no texto da Flora Fluminensis são de grande utilidade no estudo taxonômico das plantas alí descritas. Sem dúvida, os topônimos e os aspectos fisionômicos apresentados permitem, na maioria das vezes, um reconhecimento preciso dos locais e ambientes onde elas foram coletadas. 
As principais referências geográficas (Figura 1) e habitats citados nos textos sobre as espécies de Leguminosae são relacionadas abaixo, juntamente com os seus significados e as prováveis localizações atuais:

\section{— Referências geográficas}

“Alpium Fluminensium" - era a denominação para a cadeia de montes mais elevados da serra do Mar no Rio de Janeiro, compreendendo as serras da Estrêla e dos Orgãos (Stellfeld, 1948).

"Fluvii Parahyba" - atual rio Paraiba do Sul. No final do século XVIII o vale do Paraíba era penetrado pelo caminho que ligava as regiões de São Paulo à Paratí. Portanto é mais provavel que as plantas descritas por Frei Vellozo foram coletadas neste roteiro.

"Itacurussú" - atual cidade de Itacuruçá/RJ.

"Pagum Cunha" - atual cidade de Cunha/SP.

"Parochiae Campo Grande" - atual bairro de Campo Grande na cidade do Rio de Janeiro.

"Phamacopolis" - atual município de Paratí/RJ, que na época de Frei Vellozo compreendia a freguesia eclesiástica do Nossa Senhora dos Remédios.

"Praedium Boavista" - lugar no caminho entre Paratí/RJ e Cunha/SP, onde pousavam provavelmente os tropeiros (Stellfeld 1948).

"Regiun Praedium Sanctae Crucis" - atual bairro de Santa Cruz na cidade do Rio de Janeiro, onde no período colonial foi estabelecida uma fazenda de propriedade da Corôa para cultivo de chá-da-india. Stellfeld (1948) estimou a sua área em 50 léguas quadradas.

"Sacellum D. Antonii Joary" - atual Joarí no bairro de Campo Grande, cidade do Rio de Janeiro.

\section{- Hábitats}

"habitat maritimis" - denominação geral para as formações vegetais litorâneas, incluindo principalmente as formações de restinga, desde arbustiva até arbórea.

"In campis" - denominação comum para as formações campestres naturais ou antrópicas.

"In campis apricis mediterraneis transalpinis" - provavelmente é a denominação para as formações campestres do vale do rio Paraíba do Sul e da serra da Mantiqueira. Provavelmente, inclui também os cerrados, pois algumas leguminosas citadas para este hábitat são espécies típicas desta formação.

"In campis maritimis" - formações campestres litorâneas, incluindo as restingas, dunas e praias.

"In fruticetis inundatis" - formações arbustivas brejosas da planície costeira.

"In fruticetis mediterraneis" - denominação comum provável para as formações não florestais ou antrópicas das encostas da serra do Mar e do vale do rio Paraíba do Sul. 


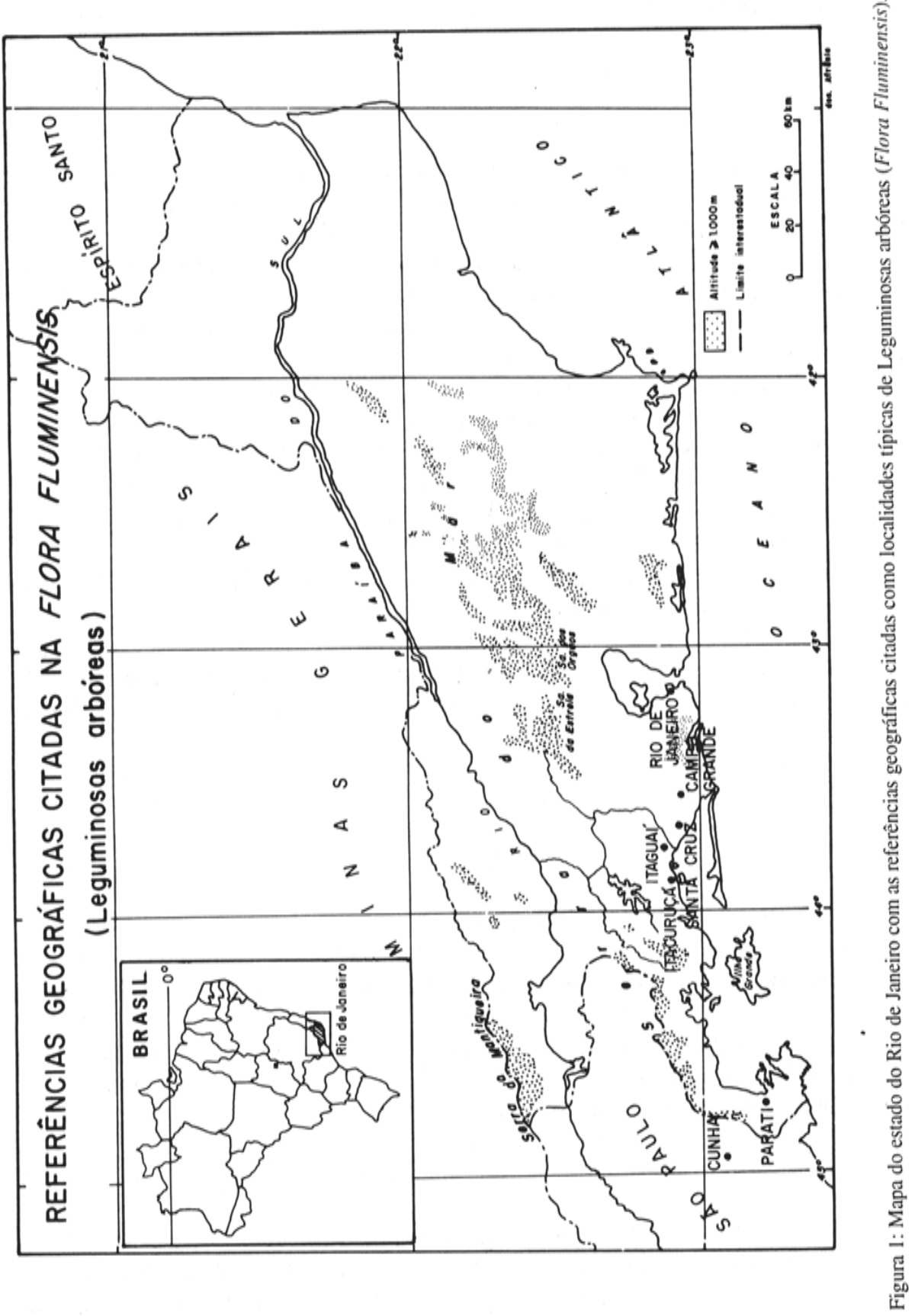


"In silvis maritimis" - formações florestais da planície costeira e das elevações litorâneas. Nesta denominação também foram incluidos os manguezais (silvis maritimis ad littora maris), hábitat de Dalbergia ecastophyllum (L.)Taub.

"In silvis mediterraneis" - formações florestais das encostas da serra do Mar, geralmente em suas porções mais afastadas do litoral, bem como do vale do rio Paraíba do Sul.

As coleções botânicas e os tipos

A localização do material botânico procedente das coletas de Frei Vellozo é hoje incerta. Borgmeier (1961) esclareceu que por volta de 1798 as plantas foram enviadas ao Museu Real de Lisboa, onde provavelmente foram incluidas no herbário pelo proprio autor da Flora Fluminensis. A única referência sobre o seu possível destino foi dada por Bocage (1862), que citou 117 plantas de Frei Vellozo na relação daquelas entregues em 1808 a G. Saint Hilaire para serem remetidas à Paris.

Durante o presente estudo, foram examinados os materiais botânicos referentes às leguminosas arbóreas do Rio de Janeiro depositados nos herbários do Muséum National d'Histoire Naturelle (P), da Universidade de Coimbra (COI) e da Escola Politécnica da Uniiversidade de Lisboa (LISU). No entanto, os resultados foram infrutíferos, pois não foram localizados os materiais tipos das espécies descritas por Vellozo e nem foram obtidas informações sobre a presença desta coleção de plantas em Portugal e na França. Em decorrência desta situação, as estampas da Flora Fluminensis(Vellozo 1831) continuam sendo consideradas os lectótipos das espécies.

\section{Resultados e conclusões}

Na Flora Fluminensis foram publicadas 61 espécies de leguminosas arbóreas. No texto da primeira edição (Vellozo 1829) foram descritas apenas 33 espécies, ilustradas no volume 11 das iconografias (Vellozo 1831) juntamente com outras 28 espécies. Posteriormente todas as espécies foram descritas no texto da segunda edição (Vellozo 1881).

A delimitação correta dos táxons exigiu uma criteriosa análise dos caracteres morfológicos das diagnoses e das estampas. Os locais e os hábitats assinalados por Vellozo, após uma interpretação e atualização das referências geográficas e fisionômicas, proporcionaram, na maioria das vezes, o reconhecimento preciso do habitat das espécies. Isto foi muito esclarecedor, principalmente para aqueles binômios onde somente a análise da diagnose e/ou da estampa não permitiu uma decisão definitiva sobre a nomenclatura atual. Em todas as espécies foram revisados os limites reconhecidos em trabalhos posteriores, principalmente aqueles assinalados em Bentham $(1860,1876)$, e, quando necessário, foram resgatados os conceitos originais.

Como resultado da análise dos táxons são propostas 2 novas combinações, e apresentada uma lista com 58 espécies atualizadas e 3 espécies duvidosas. 
Novas combinações

Tachigali paratyensis (Vell.)H.C. Lima comb. nov.

=Cassia paratyensis Vell. Fl. Flum. 168 1829[1825]; Tipo: "Habitat silvis Pharmacopolitanis". Icon. 4: tab. 70. 1831 [1827].

Lonchocarpus cultratus (Vell.)Az.-Tozzi et H.C. Lima comb. nov. =Pterocarpus cultratus Vell. Fl. Flum. 301.1829[1825]; Tipo: "Habitat silvis maritimis". Icon. 7: 95. 1831 [1827].

Lista das espécies

1. Abrus arboreus Vell. Fl. Flum. 302. 1829 [1825]; Icon. 7: tab. 99. 1831 [1827]. Nomenclatural atual: Ormosia arborea (Vell.) Harms.

2. Bauhinia aculeata Vell. Fl. Flum. 171. 1829 [1825]; Icon. 4: tab. 83.1831 [1827]. Nomenclatura atual: Bauhinia forficata Link.

3. Caesalpini vesicaria auct. non L., Vell. Fl. Flum. 172. 1829 [1825]; Icon. 4: tab. 89. 1831 [1827]. Nomenclatura atual: Caesalpinia echinata Lam.

4. Cassia disperma Vell. Fl. Flum. 167. 1829 [1825]; Icon. 4: tab. 69. 1831 [1827]. Nomenclatura atual: Peltophorum dubium (Spreng.) Taub.

5. Cassia ensiformis Vell. Fl. Flum. 170. 1829 [1825]; Icon. 4: tab. 79. 1831 [1827]. Nomenclatura atual: Chamaecrista ensiformis (Vell.) H.S. Irwin et Barneby

6. Cassia fluminensis Vell. Fl. Flum. 168. 1829 [1825]; Icon. 4: tab. 72.1831 [1827]. Nomenclatura atual: Dimorphandra exaltata Schott .

A planta de Vellozo não foi citada por Silva (1976). Entretanto, a estampa da Flora Fluminensis não deixa dúvidas sobre a sinonimização aqui apresentada.

7. Cassia javanica auct. non L., Vell. Fl Flum. 168. 1829 [1825]; Icon. 4: tab. 73.1831 [1827]. Nomenclatura atual: Cassia leptophylla Vogel.

Vogel (1837) tratou esta espécie como um sinônimo de C. leptophylla. Embora Irwin \& Barneby (1982) não tenham concordado com este ponto de vista, a estampa da Flora Fluminensis mostra uma planta com inflorescência no ápice do ramo, provida de brácteas persistentes e flores longo pediceladas, que coincidem com C. leptophylla, que é a única espécie com tais características no Brasil Sudeste.

8. Cassia parahyba Vell. Fl. Flum. 168. 1829 [1825]; Icon. 4: tab. 71.1831 [1827]. Nomenclatura atual: Schizolobium parahybum (Vell.) Blake. 

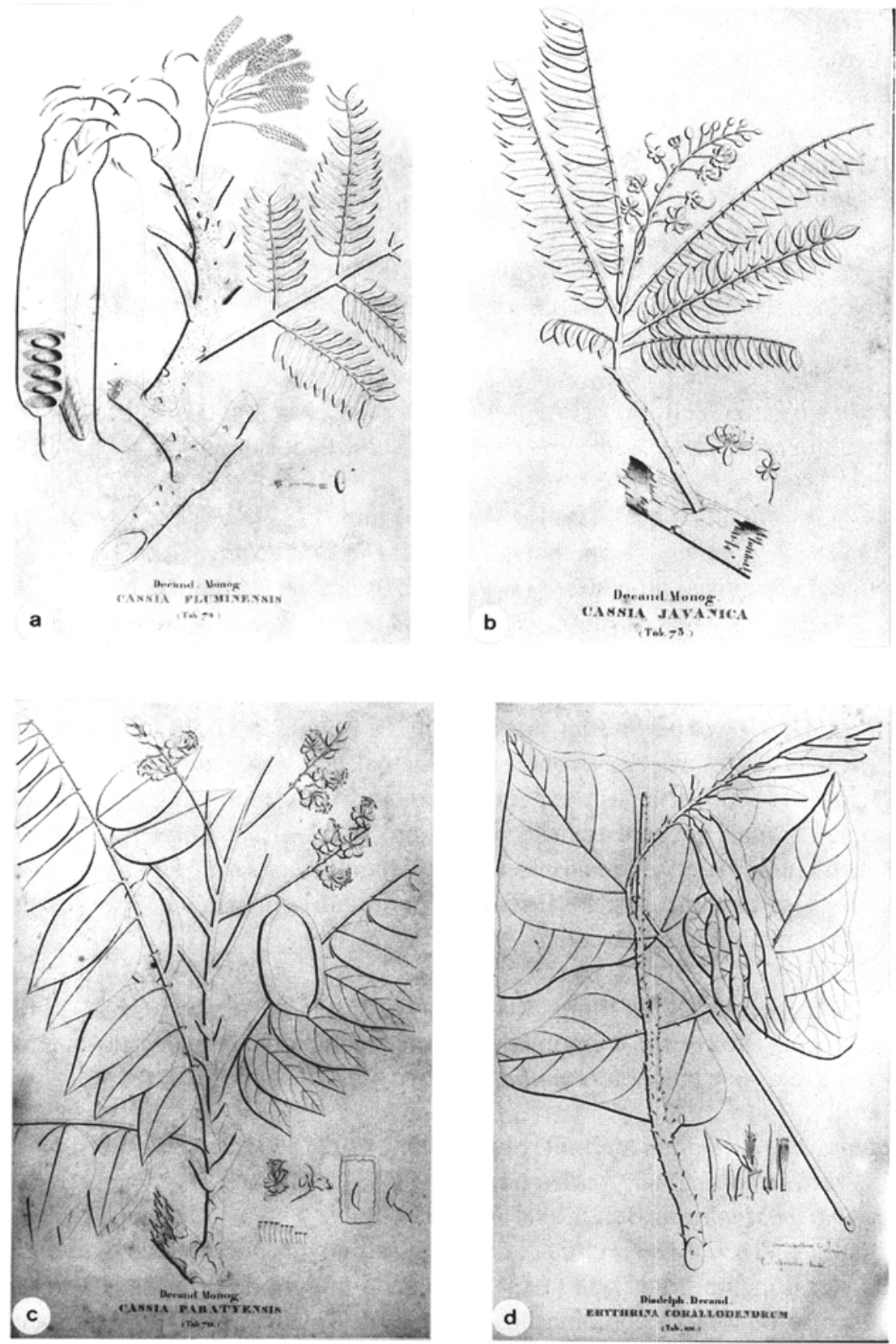

Figura 2: a. Cassia fluminensis; b. Cassia javanica; c. Cassia paratyensis; d. Erythrina corallodendron. 
9. Cassia paratyensis Vell. Fl. Flum. 168. 1829 [1825]; Icon. 4: tab. 70. 1831 [1827]. Nomenclatura atual: Tachigali paratyensis (Vell.) H.C. Lima nov.comb.

$=$ Tachigalia multijuga Benth.

A estampa da Flora Fluminensis (Figura 2a) mostra características morfológicas idênticas à única espécie do gênero Tachigali ocorrente no Brasil Sudeste ( $T$. multijuga Benth.). Em decorrência da prioridade do binômio de Vellozo, é aqui proposta uma nova combinação. O nome Tachigalia tem uso frequente na literatura botânica, porém Lewis(1987) restabeleceu a grafia correta "Tachigali" para o gênero.

10. Cassia semi-falcata Vell. Fl. Flum. 167. 1829 [1825]; Icon. 4: tab. 68. 1831 [1827].Nomenclatura atual: Senna multijuga var. lindleyana (Gardn.) H.S. Irwin et Barneby

11. Cassia silvestris Vell. Fl. Flum. 169. 1829 [1825]; Icon. 4: tab. 78. 1831 [1827]. Nomenclatura atual: Senna silvestris (Vell.) H.S. Irwin et Barneby

12. Copaifera officinalis auct. non L., Vell. Fl. Flum. 172. 1829 [1825]; Icon. 4: tab. 88. 1831 [1827] - syn. nov. Nomenclatura atual: Copaifera langsdorfii Desf.

Na última revisao do gênero, Dwyer (1950) não fez referência ao binômio de Vellozo. As características da descrição e da estampa da Flora Fluminensis permitem coloca-la como um sinônimo de $C$. langsdorfii.

13. Erythrina corallodendron auct. non L., Vell. Fl. Flum. 303. 1829 [1825]; Icon. tab. 7: 101. 1831 [1827] - syn. nov. Nomenclatura atual: Erythrina speciosa Andr.

Bentham (1860) citou esta espécie como um sinônimo duvidoso de E. corallodendron L. A mais recente revisão do gênero (Krukoff \& Barneby, 1974) não menciona o binômio de Vellozo. Entretanto, a estampa da Flora Fluminensis (Figura 2d) mostra algumas características florais que permitem com toda precisão reconhecêlo como um sinônimo de E. speciosa.

14. Erythrina verna Vell. Fl. Flum. 304.1829 [1825]; Icon. 7: tab. 102. 1831 [1827].

Bentham (1862) citou o binômio de Vellozo como um táxon duvidoso. Krukoff (1939) restabeleu-o e colocou E. mulungu Mart. em sua sinonímia.

15. Lumbricidia anthelmia Vell. Fl. Flum. 305. 1829 [1825]; Icon. 7: tab. 104. 1831 [1827]. Nomenclatura atual: Andira anthelmia (Vell.) Macbr.

= Andira stipulacea Benth. syn. nov.

Bentham (1837 e 1862) citou $L$. anthelmia como um sinônimo de A. anthelminthica. Posteriormente, Macbride (1934) aplicando a regra de prioridade apresentou para a espécie uma nova combinação em Andira. Toledo (1946) e Mattos (1979) aceitaram tal proposição e também incluiram $A$. anthelminthica na sinonímia desta espécie. Dentro do conceito reconhecido por estes autores, o táxon de Vellozo foi incluido entre aqueles que possuem estípulas pequenas e caducas. Entretanto, a 


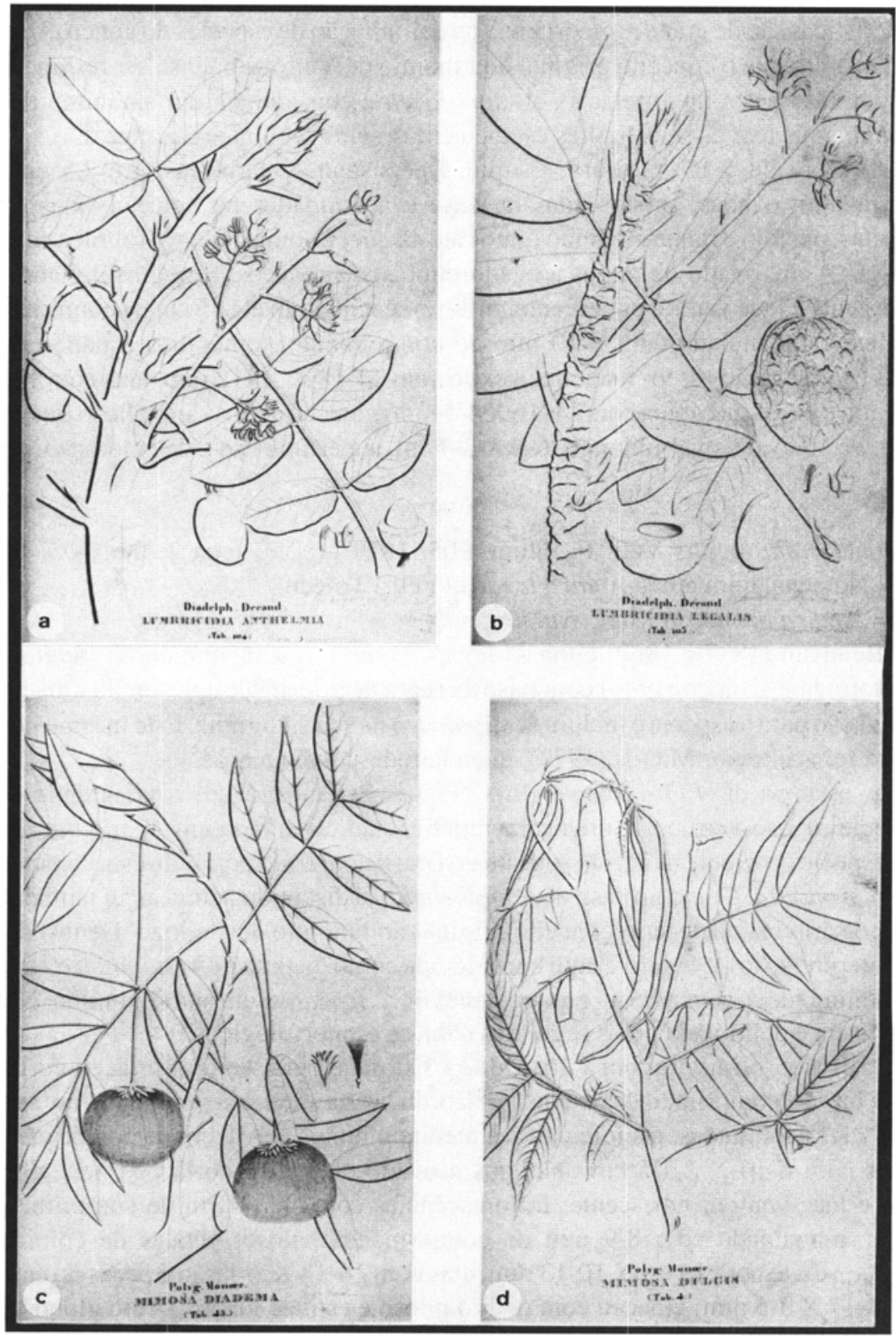

Figura 3: a. Lumbricidia anthelmia; b. Lumbricidia legalis; c. Mimosa diadema; d. Mimosa dulcis. 
estampa da Flora Fluminensis (Figura 2b), que ilustra L. anthelmia, mostra uma planta com estípulas grandes, persistentes e concentradas no ápice do ramo. Estas características são de grande importância na delimitação de espécies do gêneroAndira e demonstram que o conceito original do binômio de Vellozo precisa ser restabelecido. Com base nesta interpretação, A. stipulacea é considerada um sinônimo de $A$. anthelmia, que tem os seus limites estabelecidos pelos seguintes caracteres:

"Árvore de 4-15 m altura. Estípulas persistentes, cartáceas, 1,6-2,5 cm de comprimento, ovadas, subcordadas na base e acuminadas no ápice. Folhas 7-15 folíoladas; pecíolo e raque medindo juntos até $45 \mathrm{~cm}$ de comprimento; folíolos com 5$12 \times 2,5-4 \mathrm{~cm}$, ovado-oblongos a ovado-elípticos, cartáceos, face dorsal glabra ou glabrescente e face ventral pubescente. Inflorescências com até $45 \mathrm{~cm}$ de comprimento; cálice campanulado com 8-10 mm de comprimento, tomentoso a pubescente; pétalas de coloração róseo- magenta, vexilo com 14-18 X 10-12 mm, alas com 13-17 X 3-4 mm e peças da carena com 11-16 X 4-5 mm; gineceu com ovário piloso e estilete glabro. Fruto oval a oval-oblongo, 6-8 X 3-4 cm, superfície lisa e de coloração verde escura".

16. Lumbricidia legalis Vell. Fl. Flum. 205. 1829 [1825]; Icon 7: tab. 105. 1831 [1827].Nomenclatura atual: Andira legalis (Vell.) Toledo.

= Andira. frondosa Mart. syn. nov.

Bentham (1837 e 1862) citou L. legalis como um sinônimo de A. stipulacea. Posteriormente, Toledo (1946) com base na regra de prioridade apresentou uma nova combinação para a espécie e incluiu A. stipulacea na sua sinonímia. Este mesmo ponto de vista foi aceito por Mattos (1979), quando redescreveu a espécie.

A estampa da Flora Fluminensis (Figura 2c) mostra um fruto grande com superfície rugoso-verrucosa, uma característica não observada em A. stipulacea. A única espécie ocorrente na região sudeste do Brasil com fruto portando esta característica é A. frondosa. Como no caso de A. anthelmia, já discutido acima, aqui também se faz necessário restabelecer o conceito original do binômio de Vellozo. Dentro desta nova interpretação, A. legalis é aqui considerada como distinta de $A$. stipulacea - agora um sinônimo de A. anthelmia - e passa a incluir A. frondosa em sua sinonímia. Neste conceito ela é delimitada pelos seguintes caracteres morfológicos:

"Arvoreta ou árvore com 3-16 m altura. Estípulas persistentes, cartáceo-coriáceas, $2-3 \mathrm{~cm}$ de comprimento, ovadas, subcordadas na base e acuminadas no ápice. Folhas 11-17 folioladas; pecíolo e raque medindo juntos até $50 \mathrm{~cm}$ de comprimento; folíolos com 6-10 X 2,5-5 cm oblongos a ovado-oblongos, coriáceos, face dorsal glabra e face ventral pubescente. Inflorescências com até $60 \mathrm{~cm}$ de comprimento; cálice campanulado com 8-9 mm de comprimento, viloso; pétalas de coloração magenta; vexilo com 15-18 X 10-13 mm, alas com 14-18 X 3-4 mm e peças da carena com 14-17 X 3-5 mm; gineceu com ovário piloso e estilete glabro. Fruto globoso ou ovoide-globoso, 10-13 X 7-10 cm, superfície rugoso- verrucosa e de coloração pardoacinzentada". 
17. Mimosa barbadetiman Vell. Fl. Flum. Icon. 11: tab. 7. 1831 [1827]; Arch. Mus. Nac. Rio de Janeiro 5: 431. 1881. Nomenclatura atual: Stryphnodendron adstringens (Mart.) Coville.

18. Mimosa colubrina Vell. Fl. Flum. Icon. 11: tab. 16. 1831 [1827]; Arch. Mus. Nac. Rio de Janeiro 5: 434. 1881. Nomenclatura atual: Anadenanthera colubrina (Vell.) Brenan.

19. Mimosa contortisiliqua Vell. Fl. Flum. Icon. 11 : tab. 25. 1831 [1827];Arch. Mus. Nac. Rio de Janeiro 5: 436. 1881. Nomenclatura atual: Enterolobium contortisiliquum (Vell.) Morong.

20. Mimosa crocea Vell. Fl. Flum. Icon. 11: tab. 17. 1831 [1827]; Arch. Mus. Nac. Rio de Janeiro 5: 434. 1881. Nomenclatura atual: Swartzia simplex var. grandiflora (Raddi) Cowan .

21. Mimosa cylindrica Vell. Fl. Flum. Icon. 11: tab. 9. 1831 [1827]; Arch. Mus. Nac. Rio de Janeiro 5: 432. 1881. Nomenclatura atual: Inga cylindrica (Vell.) Mart.

22. Mimosa diadema Vell. Fl. Flum. Icon. 11: tab. 46. 1831 [1827]; Arch. Mus. Nac. Rio de Janeiro 5: 441. 1881. Nomenclatura atual: Inga diadema (Vell.) Mart.

Martius(1837) transferiu Mimosa diadema para o gênero Inga. Esta proposição também foi aceita por Bentham (1875 e 1876). Rodrigues (1982) não tratou desta espécie por não ter encontrado material botânico procedente do estado do Rio de Janeiro.

Vellozo (1881) descreveu uma planta de caule lenhoso, ereto e ramificado, folha com 5-6 jugas, pecíolo comum desprovido de glândula e inflorescência pêndula com flores alvas (Figura 3a). No Rio de Janeiro, até o momento não foi reeencontrada nenhuma espécie do gênero Inga com este conjunto de características.

23. Mimosa dulcis Vell. Fl. Flum. Icon. 11: tab. 4. 1831 [1827]; Arch. Mus. Nac. Rio de Janeiro 5: 431. 1881. Nomenclatura atual: Inga dulcis (Vell.) Mart.

= Inga striata Benth. syn. nov.

Bentham (1875 e 1876) considerou esta espécie um sinônimo de I. affinis DC. Entretanto, a morfologia do fruto e das bractéolas persistentes ilustradas na estampa de Vellozo (Figura 3b), demonstra tratar-se de outra espécie. Inga dulcis é aqui restabelecida no seu conceiro original e incluida I. striata na sua sinonímia.

24. Mimosa flageliformis Vell. Fl. Flum. Icon. 11: tab. 27. 1831 [1827]; Arch. Mus. Nac. Rio de Janeiro 5: 436. 1881. Nomenclatura atual: Inga flageliformis (Vell.) Mart.

25. Mimosa incurialis Vell. Fl. Flum. Icon. 11: tab. 24. 1831 [1827]; Arch. Mus. Nac. Rio de Janeiro 5: 436. 1881. Nomenclatura atual: Pithecellobium incuriale (Vell.) Benth. 

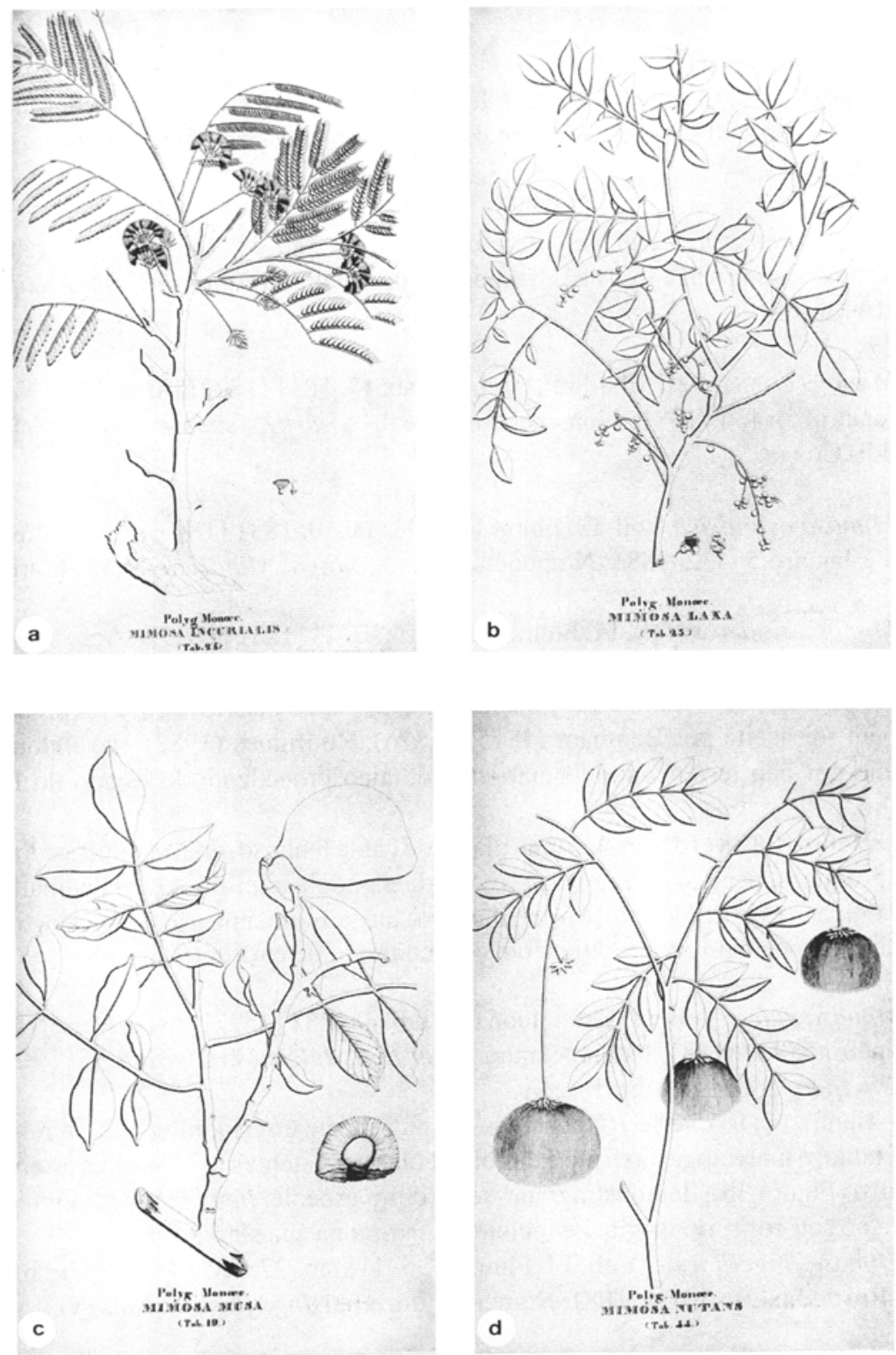

Figura 4. a. Mimosa incurialis; b. Mimosa laxa; c. Mimosa musa; d. Mimosa nutans. 
Em virtude de erro na impressão, o nome desta espécie, juntamente com a diagnose, não foi publicado no texto da Fl. Fluminensis (Vellozo, 1881). Apenas algumas observações sobre a planta foram divulgadas após a diagnose de Mimosa laxa. Com base na estampa de Vellozo, Bentham (1845) transferiu esta espécie para Pithecellobium. Nielsen (1981) apontou diferenças marcantes entre $P$. incuriale e as demais espécies deste gênero e, preliminarmente, incluiu-a em um táxon provisório (Gênero C). R.C. Barneby e J. Grimes (com. pers.), que estão atualmente revisando as espécies de Pithecellobium s. lato do Novo Mundo, têm um trabalho inédito propondo a transferência da espécie de Vellozo para o novo gênero Leucochloron.

26. Mimosa inga auct, non L. Vell: Fl. Flum. Icon. 11: tab. 3.1831 [1827]; Arch. Mus. Nac. Rio de Janeiro 5:431. 1881. Nomenclatura atual: Inga edulis Mart.

Martius(1837) transferiu Mimosa inga para o gênero Inga, de acordo com as regras nomenclaturais, propondo um novo nome (Inga edulis) em substituição ao de Vellozo.

27. Mimosa laxa Vell. Fl. Flum. Icon. 11: tab. 23. 1831 [1827]; Arch. Mus. Nac. Rio de Janeiro 5: 435. 1881 - sin. nov. Nomenclatura atual: Swartzia apetala Raddi var. apetala.

O texto das observações sobre esta espécie foi suprimido por erro de impressão. As observações divulgadas na página 436 (Vellozo, 1881) dizem respeito a $M$. incurialis. Cowan (1968) afirmou que M. laxa é certamente uma espécie de Swartzia. Porém, considerou a descrição e a estampa insuficientes para permitir a aplicação do nome de Vellozo. Entretanto, a referida estampa mostra as flores apetalas e as folhas com (2)3 ou 4 jugas, justificando sua inclusão na sinonímia de $S$. apetala var.apetala, o único táxon com estas características ocorrente no Rio de Janeiro.

28. Mimosa longisiliqua Vell. Fl. Flum. Icon. 11: tab. 15. 1831 [1827]; Arch. Mus. Nac. Rio de Janeiro 5: 433. 1881. Nomenclatura atual: Pseudopiptadenia contorta (DC.) G.P. Lewis et M.P. Lima.

29. Mimosa lusoria Vell. Fl. Flum. Icon. 11: tab. 14. 1831 [1827]; Arch. Mus. Nac. Rio de Janeiro 5: 433. 1881. Nomenclatura atual: Pithecellobium lusorium (Vell.) Benth.

R. Barneby e J. Grimes (com. pers.) concordam com a transferência de $P$. lusorium para o gênero Abarema. Entretanto, um binômio mais antigo (Inga brachystachya $\mathrm{DC}$.) foi citado por Bentham (1845) como sinônimo de P. lusorium. Um futuro estudo se faz necessário para uma solução definitiva deste problema nomenclatural. Se a sinonimia for confirmada, uma nova combinação deverá ser apresentada.

30. Mimosa monjollo Vell. Fl. Flum. Icon. 11: tab. 26. 1831 [1827]; Arch. Mus. Nac. Rio de Janeiro 5: 436. 1881. Nomenclatura atual:Enterolobium monjollo (Vell.) Mart. 
31. Mimosa musa Vell. Fl. Flum. Icon. 11: tab. 19. 1831 [1827]; Arch. Mus. Nac. Rio de Janeiro 5: 434. 1881 - syn. nov. Nomenclatura atual: Swartzia langsdorffii Raddi. Bentham (1870) observou ser esta espécie muito próxima de $S$. langsdorffii. Posteriormente, Cowan (1968) inclui-a na lista de espécies excluidas de Swartzia por considerar a descrição e a estampa de Vellozo insuficientes para permitir a aplicação do nome. Entretanto, os frutos grandes, comprimidos e indeiscentes, as sementes com arilo muito desenvolvido e circundante e as folhas com raque alada e folíolos elípticos a lanceolados, características ilustradas na estampa da Flora Fluminensis, quando comparados com as espécies ocorrentes no estado do Rio de Janeiro, não deixam dúvidas que o binômio de Vellozo deve ser colocado na sinônímia de $S$. langsdorffii.

32. Mimosa nutans Vell. Fl Flum. Icon. 11: tab. 44. 1831 [1827]; Arch. Mus. Nac. Rio de Janeiro 5: 441. 1881. Nomenclatura atual: Inga nutans (Vell.) Mart.

Vellozo (1881) descreveu uma planta de caule lenhoso, declinado e pouco ramificado, folhas 4-5 jugas, pecíolo comum desprovido de glândulas, inflorescência pêndula, flores vermelhas e frutos comprimidos (Figura 3c). Bentham (1875 e 1876) ao redescrever I. nutans apresentou características distintas da descrição de Vellozo, as quais são aqui consideradas como pertencentes a I. tenuis. Portanto, o conceito original do binômio de Vellozo deve ser restabelecido e I. nutans senso Bentham incluida na sinônímia de I. tenuis.

Embora desde a sua descrição a espécie não tenha sido mais observada no Rio de Janeiro, coletas recentes reencontraram-na em matas costeiras do norte do Espírito Santo.

33. Mimosa pacoba Vell. Fl. Flum. Icon. 11: tab. 20. 1831 [1827]; Arch. Mus. Nac. Rio de Janeiro 5: 435. 1881. Nomenclatura atual: Swartzia flaemingii Raddi var. flaemingii.

34. Mimosa plana Vell. Fl. Flum. Icon. 11: tab. 10. 1831 [1827]; Arch. Mus. Nac. Rio de Janeiro 5: 432. 1881. Nomenclatura atual: Inga cordistipula Mart.

Vellozo apresentou simultaneamente duas espécies distintas sob o nome $M$. plana (Icon. 11: tab. 10 e 28). Martius (1837) transferiu a espécie ilustrada na tabula 10 para o gênero Inga com um novo nome (Inga cordistipula).

35. Mimosa plana Vell. Fl. Flum. Icon. 11: tab. 28. 1831 [1827]; Arch. Mus. Nac. Rio de Janeiro 5: 437. 1881. Nomenclatura atual: Acacia riparia H.B.K.

Como já foi discutido anteriormente, duas espécies foram descritas simultaneamente sob o binômio $M$. plana. A espécie descrita na tabula 28 foi considerada um provável sinônimo de A. riparia (Bentham, 1875 e 1876).

36. Mimosa pulchra Vell. Fl. Flum. Icon. 11: tab. 18. 1831 [1827]; Arch. Mus. Nac. Rio de Janeiro 5: 434. 1881. Nomenclatura atual: Swartzia langsdorffii Raddi. 

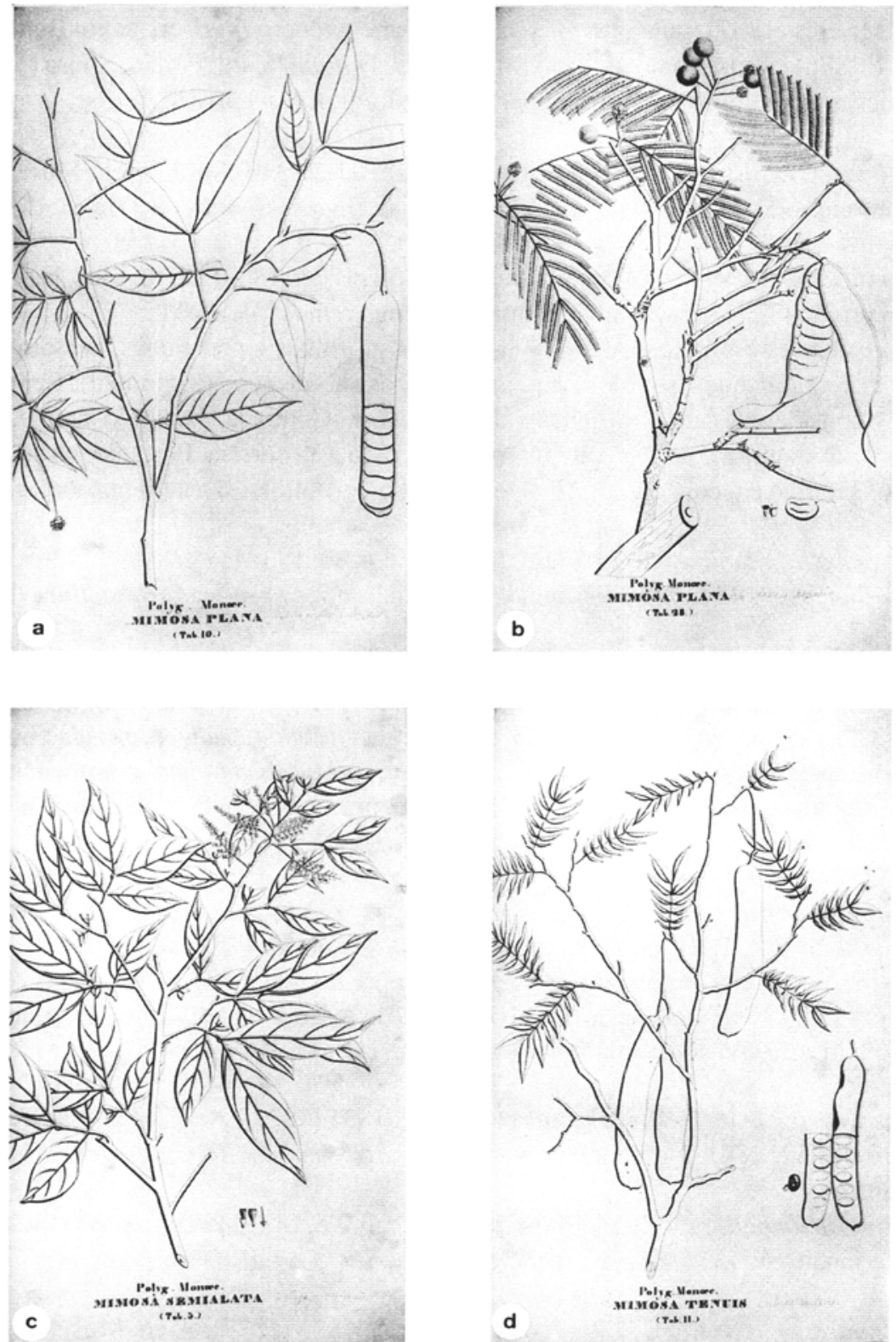

Figura 5. a. Mimosa plana; b. Mimosa plana; c. Mimosa semialata; d. Mimosa tenuis. 
37. Mimosa semialata Vell. Fl. Flum. Icon. 11: tab. 5. 1831 [1827]; Arch. Mus. Nac. Rio de Janeiro 5: 431. 1881. Nomenclatura atual: Inga semialata (Vell.) Mart.

Martius (1837) transferiu M. semialata para o gênero Inga, enquanto Bentham (1875 e 1876) citou-a como um sinônimo de I. marginata Willd. Porém, Sousa (1993) considerou este último um nome supérfluo e reabilitou I. semialata.

38. Mimosa sessilis Vell. Fl. Flum. Icon. 11: tab. 21. 1831 [1827]; Arch. Mus. Nac. Rio de Janeiro 5: 435. 1881. Nomenclatura atual: Inga sessilis (Vell.)Mart.

39. Mimosa tenuis Vell. Fl. Flum. Icon. 11: tab. 11. 1831 [1827]; Arch. Mus. Nac. Rio de Janeiro 5: 432. 1881. Nomenclatura atual: Inga tenuis (Vell.) Mart.

A planta descrita por Vellozo (1881) possui folhas com 7 jugas, pecíolo subalado e com glândulas, folíolos pequenos e frutos subfalcados (Figura 3d). Bentham (1876) considerou-a uma variedade de I. nutans. Como já discutido acima, nos comentários sobre $M$. nutans, esta interpretação nao está correta. Portanto, o status ao nível específico e o conceito original do binômio de Vellozo são aqui restabelecidos.

40. Mimosa terminalis Vell. Fl. Flum. Icon. 11: tab. 30. 1831 [1827]; Arch. Mus. Nac. Rio de Janeiro 5: 437. 1881. Nomenclatura atual: Macrosamanea pedicellare (DC.) Kleinh.

Bentham (1876) citou esta espécie como um sinônimo de Pithecellobium polycephallum. Entretanto, o exame da estampa de Vellozo não deixa dúvidas sobre a mesma identidade de M. terminalis com Pithecellobium pedicellare. Kleihonnte (1940) transferiu esta última espécie para o gênero Macrosamanea, a nomenclatura aceita atualmente, embora R.C. Barneby e J. Grimes (com. pers.), considerem mais apropriado transferi-la para o novo gênero Balizia.

41. Mimosa tetraphylla Vell. Fl. Flum. 11: tab. 8. 1831 [1827]; Arch. Mus. Nac. Rio de Janeiro 5: 432. 1881. Nomenclatura atual: Inga laurina (Sw.) Willd.

Martius (1837) transferiu $M$. tetraphylla para o gênero Inga, no entanto Bentham (1875 e 1876) citou-a como um sinônimo de I. fagifolia Willd. Atualmente este último tem sido considerado um nome ilegítimo (Sousa, 1993).

42. Mimosa triphylla Vell. Fl. Flum. 11: tab. 22. 1831 [1827]; Arch. Mus. Nac. Rio de Janeiro 5: 432. 1881. Nomenclatura atual: Swartzia myrtifolia var.elegans (Schott) Cowan.

43. Mimosa umbellata Vell. Fl. Flum. Icon. 11: tab. 12. 1831 [1827]; Arch. Mus. Nac. Rio de Janeiro 5: 433. 1881. Nomenclatura atual:Inga affinis DC.

44. Mimosa vaga Vell. Fl. Flum. Icon. 11: tab. 13. 1831 [1827]; Arch. Mus. Nac. Rio de Janeiro 5: 433. 1881. Nomenclatura atual: Pithecellobium cochliocarpum (Gomez) Macbr.

Martius (1837) citou o binômio de Vellozo como sinônimo de P. avaremotemo. 
Lewis (1987) concluiu, apesar de sugerir a necessidade de um futuro estudo, que $P$. avaremotemo é um sinônimo de $P$. cochliocarpum. R. Barneby e J. Grimes (com. pers.) concordam com a transferência de $P$. cochliocarpum para o gênero Abarema.

45. Nissolia firma Vell. Fl. Flum. 297. 1829 [1825]; Icon. 7: tab. 83. 1831(1827). Nomenclatura atual: Machaerium firmum (Vell.)Benth.

46. Nissolia fruticosa auct. non Jacq., Vell. Fl. Flum. 298. 1829 [1825]; Icon. 7: tab. 86. 1831(1827). Nomenclatura atual: Machaerium nigrum Vog.

Bentham (1860) citou esta espécie como um sinônimo duvidoso de M. nigrum. Porém, Hoehne (1941) considerou-a distinta e apresentou uma nova combinação - $M$. fruticosum (Vell.)Hoehne. Recentemente Rudd (1987) manteve a proposta de Bentham (1860) e reincluiu $N$. fruticosa na sinonimia de M. nigrum.

47. Nissolia hirta Vell. Fl. Flum. 296. 1829 [1825]; Icon. 7: tab. 75. 1831 [1827]. Nomenclatura atual: Machaerium hirtum (Vell.)Stellfeld.

= Machaerium angustifoliaum Vog. syn. nov.

Bentham (1860) considerou esta espécie um sinônimo duvidoso de $M$. eriocarpum Benth., que é uma planta do Brasil Central ainda não observada no Rio de Janeiro. Posteriormente, Stellfeld (1944) não concordando com esta proposta apresentou uma nova combinação para o binômio de Vellozo.

As características apresentadas na estampa da Fl. Fluminensis mostram que $N$. hirta é idêntica a M. angustifolium Vog. Além disso, o habitat descrito por Vellozo (1829) - "in silvis maritimis" - coincide com aquele onde M. angustifoliumé abundante. Com base nestes argumentos, o conceito original $N$. hirta é aqui reabilitado e $M$. angustifolium incluido na sua sinonímia.

Dwyer (1965) considerou M. angustifolium um sinônimo de M. isadelphum (E. Mey) Amshoff, uma espécie ocorrente desde o México até o Suriname, Brasil, Peru e Bolivia. A descrição apresentada por este autor possui caracteres de mais de uma espécie, pois inclui dados de uma árvore e de uma liana. Portanto, um estudo mais detalhado, incluindo o exame dos tipos, de $M$. isadelphum se faz necessário para definir com maior precisão os seus possíveis sinônimos.

48. Nissolia incorruptibile Vell. Fl. Flum. 297. 1829 [1825]; Icon. 7: tab. 82.1831 [1827].Nomenclatura atual: Machaerium incorruptibile (Vell.) Benth.

Bentham(1837) transferiu $N$. incorruptibile para o gênero Machaerium, apresentando uma breve descrição baseada em material botânico coletado por Pohl. Posteriormente, em sua revisão da tribo Dalbergieae (Bentham,1860), considerou-a um sinônimo de $M$. legale e restabeleceu a nova combinação apresentada por Allemão (1852) para o nome de Vellozo.

O código de nomenclatura botânica considera que uma nova combinação tem seu conceito ligado ao basiônimo. Deste modo, mesmo que por equívoco a descrição apresentada por Bentham(1837) seja incorreta, o binômio deve ser aceito no seu 

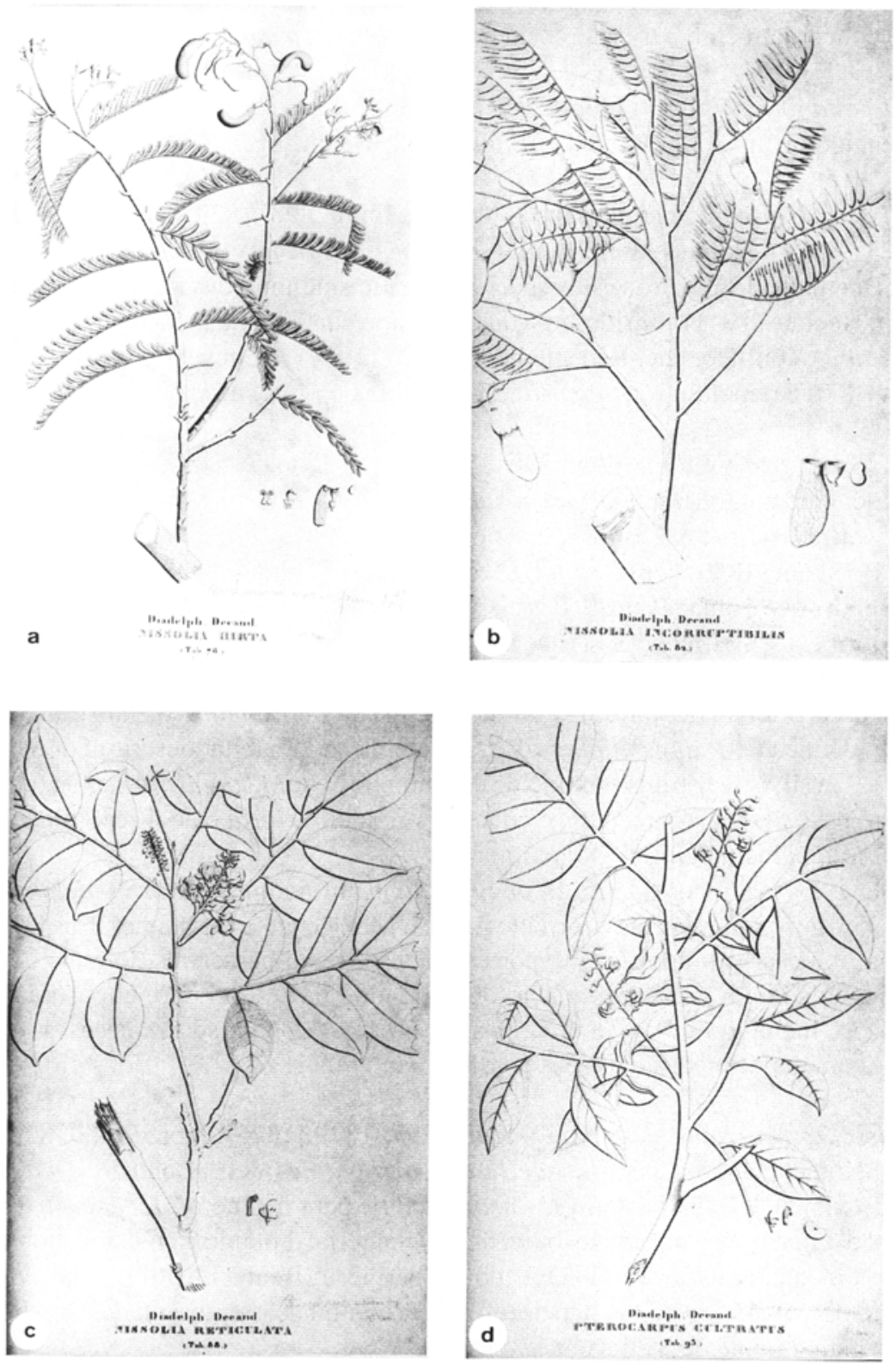

Figura 6. a. Nissolia hirta; b. Nissolia incorruptibilis; c. Nissolia reticulata; d. Pterocarpus cultratus. 
conceito original. Portanto, o nomenclatura inicialmente proposta por este autor deve ser reestabelecida. $M$. incorruptibile faz perte de um grupo de espécies muito relacionadas, que ainda necessita de estudos para uma delimitação mais precisa. Com base nos dados atuais, $M$. incorruptibile se distingue das espécies próximas pelos folíolos menores $(1,5-2 \times 0,4-0,6 \mathrm{~cm})$ e pelos frutos com indumento sub-áureo e núcleo seminífero toruloso.

49. Nissolia legalis Vell. Fl. Flum. 297. 1829 [1825]. Icon. 7: tab. 84. 1831 [1827]. Nomenclatura atual: Machaerium legale (Vell.) Benth.

50. Nissolia nictitans Vell. Fl. Flum. 295. 1829 [1825]; Icon. 7: tab. 75. 1831 [1827]. Nomenclatura atual: Machaerium nyctitans (Vell.) Benth.

N. nictitans foi transferida para o gênero Machaerium por Bentham(1837). É um táxon muito variável quanto a morfologia e ao indumento das folhas. Tal variabilidade motivou Bentham(1860) descrever $M$. gardneri, que foi posteriormente transferida por Rudd(1973) a uma variedade de $M$. nyctitans. O atual nível de conhecimento sobre a espécie sugere o uso de um conceito amplo sem separação de táxons infraespecíficos. Entretanto, um estudo para reavaliar a delimitação de $M$. nyctitans e espécies aliadas ainda se faz necessário.

51. Nissolia reticulata Vell. Fl. Flum. 299. 1829 [1825]; Icon. 7: tab. 88. 1831 [1827] - syn. nov. Nomenclatura atual: Pterocarpus rohrii Vahl.

As características morfológicas dos botões e flores da estampa de Vellozo não deixam dúvidas que se trata de uma espécie de Pterocarpus. Certamente pertence a única espécie do gênero ocorrente no Rio de Janeiro ( $P$. rohrii).

Rojo(1972) ampliou o conceito original de $P$. rohrii para incluir vários táxons com distintas características morfológicas. Este conceito precisa ser reavaliado e, se necessário, estabelecer entidades no nível infraespecífico.

52. Nissolia robusta Vell. Fl. Flum. 298. 1829 [1825]; Icon. 7: tab. 85. 1831 [1827]. Nomenclatura atual: Centrolobium robustum (Vell.) Benth. ex Mart.

53. Piscidia erythrina auct. non L., Vell. Fl. Flum. 303. 1829 [1825]; Icon. 7: tab. 100. 1831 [1827].Nomenclatura atual: Dahlstedtia pinnata (Benth.) Malme.

54. Pterocarpus cultratus Vell. Fl. Flum. 301. 1829 [1825]; Icon. 7: tab. 95. 1831 [1827].Nomenclatura atual: Lonchocarpus cultratus (Vell.)Az.-Tozzi et H.C. Lima comb. nov.

= Lonchocarpus guilleminianus (Tul.) Malme sin. nov.

Espécie citada por Bentham(1860) como um sinônimo de Pterocarpus violaceus Vog. A morfologia do fruto ilustrada na estampa da $\mathrm{Fl}$. Fluminensis (Figura 2d) e a coloração purpurea da flor apresentada na diagnose, sustenta a transferência desta espécie para o gêneroLonchocarpus. A.M.G. Azevedo-Tozzi (Universidade Estadual 
de Campinas) atualmente está concluindo a revisão das espécies brasileiras de Lonchocarpus e considera que a espécie de Vellozo deve ser reabilitada e L. guilleminianus incluida em sua sinonimia.

55. Pterocarpus falcatus Vell. Fl. Flum. 300. 1829 [1825]; Icon. 7: tab. 93. 1831 [1827].Nomenclatura atual: Poecilanthe falcata (Vell.) Heringer.

Bentham (1860) citou esta espécie como um sinônimo de $P$. grandiflora Benth. Heringer (1952) considerando-a um táxon distinto, propôs sua reabilitação com uma nova combinação. Uma outra nova combinação posteriormente foi também apresentada por Ducke (1953). Não há duvidas que a morfologia floral demonstra que $P$. grandiflora é um sinônimo de $P$. falcata. Entretanto, como tem sido salientado por Lewis (1987), o gênero Poecilanthe requer ainda estudos de campo para uma melhor interpretação de sua variação morfológica, principalmente nas partes vegetativas.

56. Pterocarpus luteus Vell. Fl. Flum. 300. 1829 [1825]; Icon. 7: tab. 92. 1831 [1827]. Nomenclatura atual: Platymiscium luteum (Vell.) Benth.

Martius (1837) baseado em $P$. luteus propôs, a partir de manuscrito ou nome de herbário de Bentham, o novo gênero Hymenolobium Benth. ex Mart. (espécie tipo: $H$. luteum). Como admite Cowan (1958), Bentham ignorou ou acidentalmente esqueceu da publicação de Martius, quando transferiu a espécie de Vellozo para o gênero Platymiscium (Bentham, 1837) e posteriormente usou o nome Hymenolobium para outra planta (Bentham, 1860). Portanto, de acordo com os artigos 42.1 e 43.1 do Código Internacional de Botânica, Hymenolobium luteum não é validamente publicado.

As características morfológicas da estampa de $P$. luteus coincidem com aquelas do complexo de espécies de Platymiscium ocorrente no Brasil Sudeste, que com frequência vem sendo identificado como $P$. floribundum. Se elas forem consideradas sinônimos, $P$. luteum terá prioridade sobre este último binômio,. Atualmente o gênero está sendo revisado por B. B. Klitgaard (Univ. Aarhus, Dinamarca/Royal Botanic Gardens-Kew, Inglaterra).

57. Pterocarpus niger Vell. Fl. Flum. 299. 1829 [1825]; Icon. 7: tab. 91.1831 [1827]. Nomenclatura atual: Dalbergia nigra (Vell.) Allemão. ex Benth.

58. Pterocarpus polyspermus Vell. Fl. Flum. 301. 1829 [1825]; Icon. 7: tab. 94.1831 [1827]. Nomenclatura atual: Moldenhawera floribunda Schrad.

Bentham (1870) citou esta espécie como um sinônimo de M. floribunda. Em trabalho posterior, Stellfeld (1948) com base nos argumentos do botânico A.J. Sampaio apresentou uma nova combinação para o binômio de Vellozo - M. polysperma (Vell.) Stellfeld - e incluiu M. floribunda na sua sinonimia. Yakovlev (1975) considerou os dois táxons distintos e também citou M. blanchetiana Tul. como sinônimo de $M$. polysperma.

A morfologia das folhas e das flores deste complexo de espécies é suficiente para assegurar que a planta de Vellozo é um sinônimo de M. floribunda. Entretanto, 

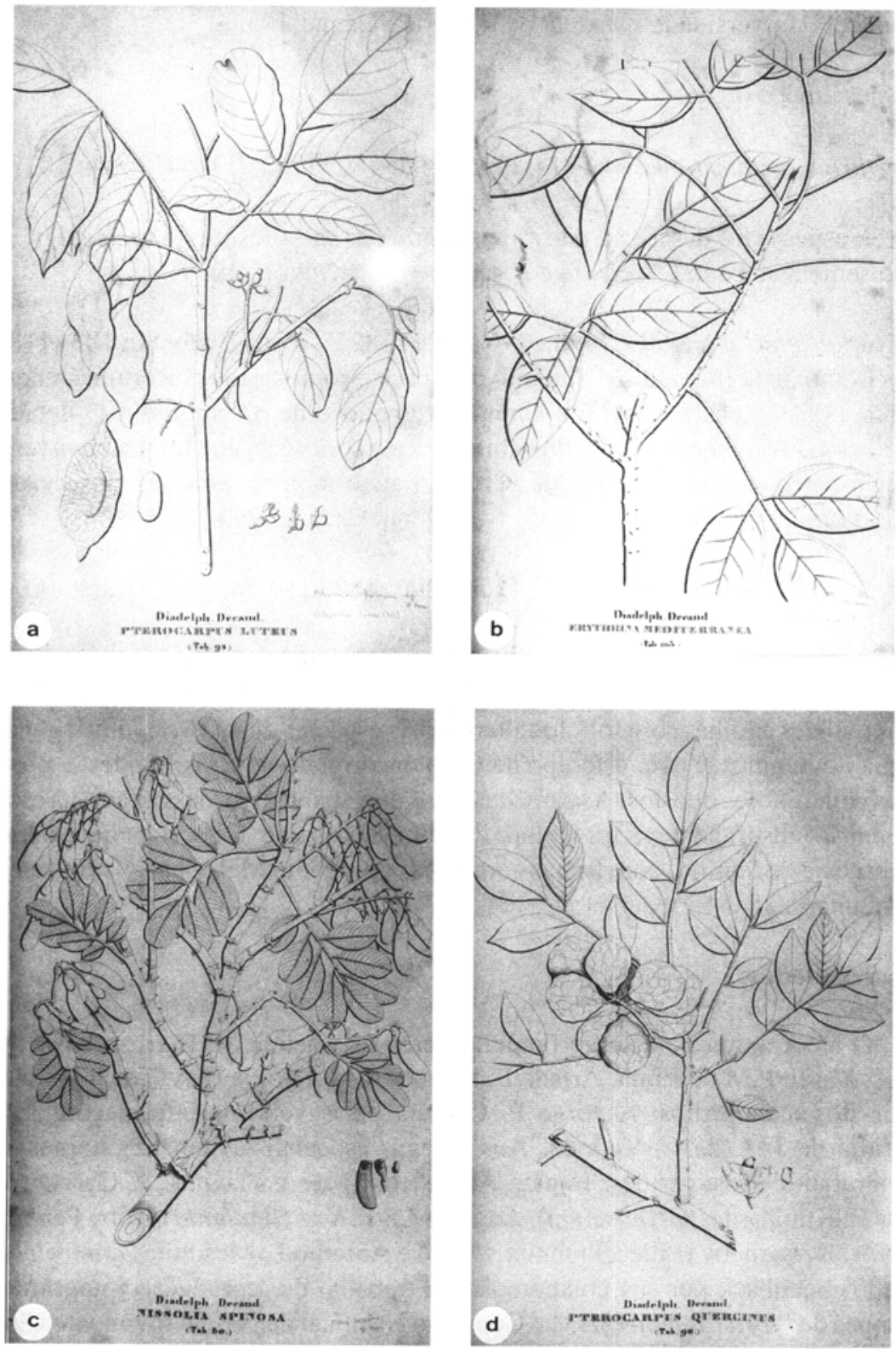

Figura 7. a. Pterocarpus luteus; b. Erythrina mediterranea; c. Nissolia spinosa; d. Pterocarpus quercimus. 
estudos sobre a variação do androceu ainda são necessários para esclarecer suas afinidades com $M$. blanchetiana. Atualmente o gênero está sendo revisado por L. Paganucci (Universidade Estadual de Feira de Santana, Bahia).

Espécies duvidosas

1. Erythrina mediterranea Vell. Fl. Flum. 304. 1829 [1825]; Icon. 7: tab. 103. 1831 [1827].

A espécie foi descrita a partir de material estéril, mostrando morfologia foliar muito semelhante a de E. falcata e E. crista-galli (Krukoff, 1939).

2. Nissolia spinosa Vell. Fl. Flum. 296. 1829 [1825]; Icon. 7: tab. 80. 1831 [1827].

Bentham (1862) citou o binômio de Vellozo como "genus incertum", enquanto Hoehne (1941) considerou-o um sinônimo duvidoso de M. nictitans. O detalhe do fruto ilustrado na estampa de Vellozo mostra a ala com venação oblíqua e convergente na região mediana. Este padrão de nervação até o momento não foi observado nas sâmaras das Leguminosas.

3. Pterocarpus quercinus Vell. Fl. Flum. 299. 1829 [1825]; Icon. 7: tab. 90.1831 [1827].

Bentham (1862) considerou $P$. quercinus um sinônimo duvidoso de Hecastophyllum monetaria Pers.(=Dalbergia $)$. A estampa de Vellozo ilustra uma planta de frutos ovoides e folhas com folíolos alternos. As espécies de Andira, o único gênero da família Leguminosae com este tipo de fruto oncorrendo no Brasil Sudeste, possuem folhas com folíolos opostos. As características apresentadas na descrição e na estampa também são insuficientes para melhor definir esta espécie. É possível que se trate de uma espécie de famílias com folhas compostas, tais como Meliaceae, Sapindaceae ou Simaroubaceae.

\section{Agradecimentos}

O autor agradece a Jorge Fontella Pereira, Graziela M. Barroso, Gwillym P. Lewis, Marli. P.M de Lima, Ariane L. Peixoto e Ana Maria G.A. Tozzi pela leitura crítica dos manuscritos. A Jorge P. Carauta pelas valiosas informações sobre a biografia de J.M. da C. Vellozo. Aos colegas especialistas em Leguminosae que colaboraram com sugestões: Irenice Alves Rodrigues e Flávia C.P. Garcia (Inga), Bente B. Klitgaard (Platymiscium), Angela M.S.F. Vaz (Bauhinia), Toby Pennington (Andira) R. Barneby (Pitlecelhobium s. lato) e Antonio L. Mesquita (Enterolobium). A Pedro Schuback por sua colaboração no trabalho de reprodução fotográfica das estampas da Flora Fluminensis. Ao Conselho Nacional de Desenvolvimento Científico e Tecnológico (CNPq) e à Fundação Botânica Margaret Mee (FBMM) pelo apoio financeiro para a realização deste trabalho, principalmente durante a visita a alguns herbários europeus. 


\section{Referências bibliográficas}

Allemão, F.F. 1852. Apontamentos que poderão servir para a história das árvores florestais do Brasil, e particularmente das do Rio de Janeiro.Trabalhos da Sociedade Vellosiana. Biblioteca Guanabarense, p. 53-56.

Bentham, G. 1837. Commentationes de Leguminosarum Generibus. Wien, IV.

Bentham, G.1845 Notes on Mimoseae with a synopsis of species (Inga). In: Hooker, (ed.) London Journ. Bot., 4: 577-622.

Bentham, G. 1860. A synopsis of the Dalbergieae, a tribe of the Leguminosae. Journ. Linn. Soc. 4, suppl.: $1-134$.

Bentham, G. 1862. Papilionaceae. In C.F.P. Martius (ed.) Flora Brasiliensis 15(1): 1-350.

Bentham, G. 1870. Leguminosae II. Swartzieae et Caesalpinieae. In C.F.P. Martius (ed.) Flora Brasiliensis 15(2): 1-254.

Bentham, G. 1875. Revision of the Suborder Mimoseae. Trans. Linn. Soc. London 30: 335-664.

Bentham, G. 1876. Leguminoase III. Mimoseae. In C.F.P. Martius (ed.) Flora Brasiliensis 15(2): 257-528.

Bocage, J.V.B. 1862. Ilustrações práticas sobre o modo de colligir, preparar e remeter produtos zoológicos para o Museu de Lisboa.

Borgmeier, 1961. A história da "Flora Fluminensis" de Frei Velloso. Publ. Arq. Nac. 48: 3-21.

Carauta, J.P.P. 1969. A data efetiva da publicação da "Flora Fluminensis". Vellozia 7: 26-33.

Carauta, J.P.P. 1972. A data efetiva da publicação da Flora Fluminensis. II. O texto impresso em 1825. Anais XXII Cong. Nac. Botanica. 141-147.

Cowan, R.S. 1958. Proposal to conserve the generic name Hymenolobium Benth against Hymenolobium Benth. ex Mart. Taxon 7: 141-142..

Cowan, R.S.1968. Swartzia (Leg. - Caesalpinioideae, Swartzieae). Flora Neotropica, Monograph n.1, $228 \mathrm{pp}$.

Damasceno, D. 1977. Introdução In: Vellozo, J.M.C. .Plantas Fluminenses descritas por Frei Velloso. Anais da Biblioteca Nacional 96: 123-133

Ducke, A. 1953. As Leguminosas de Pernambuco e Paraiba. Mem. Inst. Oswaldo Cruz 51: 417-461.

Dwyer, J.D. 1950. The Central American, West Indian and S. American Species of Copaifera (Caesalpiniaceae). Brittonia 7(3): 143-172.

Dwyer, J.D. 1965. Flora of Panama. Leguminosae - Papilionoideae (in part). Ann. Miss Bot. Gard. 52(1): $1-54$.

Heringer, E.P. 1952. Reabilitação de uma espécie de Fr. Velloso, Poecilanthe falcata (Vell.) Heringer. Arq. Serv. Florest. 6: 197-200.

Hoehne, C.F. 1941. Leguminosas - Papilionadas: Gêneros Machaerium e Paramachaerium. Flora Brasília 25(3) n. 128: 199 e 128a: 100.

Irwin, H.S. \& Barneby, R. 1982. The American Cassiinae: a synoptical revision of Leguminosae tribe Cassieae subtribe Cassiinae in the New World. Mem. N.Y. Bot. Gard. 35 (parts I \& II): 1-918.

Kleihonnte, A. 1940. Mimosaceae. In A. Pulle, (ed.) Flora of Suriname 2: 312-331.

Krukoff, B.A, 1939. The American Species of Erythrina. Brittonia (3(2): 205-337.

Krukoff, B.A. \& Barneby, R.C. 1974. Conspectus of species of the genus Erythrina. Lloydia 37(3): 332459.

Lewis, G.P. 1987. Legumes of Bahia. Royal Botanic Gardens, Kew.

Macbride, J.F. 1934. New or renamed spermatophytes mostly peruvian II. Candollea 6:1-19.

Martius, C.F. von. 1837. Herb. Florae Brasiliensis. Flora 20(2): 113-128.

Mattos, N.F. 1979. O gênero Andira (Leg. Pap.) no Brasil. Acta Amazonica 9(2): 241-266.

Nielsen, I. 1981. Tribo Ingeae Benth. In: R.M. Polhill \& P.H. Raven (ed.), Advances in Legume Systematics. Royal Botanic Gardens, Kew, p. 173-190.

Rodrigues, I.A. 1982. Contribuição à sistemática das espécies do gênero Inga P. Mill. (Leg. Mim.) ocorrentes no Estado do Rio de Janeiro. Dissertação Mestrado, UFRJ, Rio de Janeiro. 
Rojo, J.P. 1972. Pterocarpus (Leg. Papilionaceae) revised for the world. J. Cramer.

Rudd, V.E. 1973. New taxa and combinations in Machaerium (leguminosae.)-III. Phytologia 25(6): 398 403.

Rudd, V.E. 1987. Studies in Machaerium (Leguminosae)-VI. Phytologia 62(4):282-302.

Silva, M.F. da. 1986. Dimorphandra (Caesalpiniaceae). Flora Neotropica, Monograph n. 44, 128 pp.

Sousa, M. 1993. El genero Inga (Leguminosae: Mimosoideae) del sur de Mexico y Centroamerica, estudio previo para la flora mesoamericana. Ann. Miss Bot. Gard. 80: 223-269.

Stellfeld, C. 1942. A Iniciação Científica de Frei Vellozo. Tribuna. Farm. 10(11):242-244.

Stellfeld, C. 1944. Nomes vulgares das plantas estudadas por Frei Vellozo em sua Flora Fluminensis. - V. Tribuna. Farm. 12(7): 127-136.

Stellfeld, C. 1946. A toponimia latina da "Flora Fluminensis". Tribuna. Farm. 14(12): 246-248.

Toledo, J.F. 1946. Observações críticas sobre nomes de algumas plantas brasileiras. Arqs; Bot. Est. S. Paulo. Nov. ser. 2(2): 28-31.

Vellozo, J.M. da C. 1829 (1825). Florae Fluminensis... . Rio de Janeiro. 352py.

Vellozo, J.M. 1831 (1827). Florae Fluminensis Icones. Paris, 11 vol., 1640

Vellozo, J.M. 1881. Florae Fluminensis... . Arch. Mus. Nac. Rio de Janeiro 5: 461 pp.

Vogel, Th. 1837. Synopsis Generis Cassiae. Linnaea 11: 651-714.

Yakovlev, G.P. 1975. New species of Moldenhawera Schrad. (Caesalpiniaceae). Bot. Zhurn. 60(2): 219220. 